\title{
A EDUCAÇÃO COM AMOREVOLEZZA: TRANSFORMANDO O ENSINO MÉDIO
}

\section{Fernanda Valéria Pereira Moliterno' \\ Guilherme José da Silva Mariano² \\ Neide Arruda de Oliveira ${ }^{3}$}

Resumo: Rever as deficiências atuais que se inserem no ensino médio de uma escola pública estadual e desenvolver um projeto que possa contribuir para o autocrescimento e aprendizagem dos educandos, a partir dos desafios impostos pela realidade social, econômica e política, além da realidade que esse jovem divide, sendo marginalizado e prejulgado pelo bairro que mora. Deste modo, visa-se fazer a diferença na vida e na construção do indivíduo em sua formação para a cidadania, usando uma metodologia de incentivo com uso de vídeos motivacionais e dinâmicas que favoreçam o crescimento desse jovem, fazendo um trabalho com a pedagogia do amor; Amorevolezza, com o intuito de se fazer mais por esse aluno rotulado pela comunidade onde vive roubando-Ihe a perspectiva de futuro.

Palavras-chave: Ensino médio; Jovem; Trabalho; Autoestima.

\footnotetext{
${ }^{1}$ Letras/Unifatea, Brasil. E-mail:fernandamoliterno@hotmail.com.

2 Letras/Unifatea, Brasil. E-mail:guilhermejsm@hotmail.com.

3 Letras/Unifatea, Brasil. E-mail: mnoliveira9@gmail.com.
} 